\title{
Use of Pareto Principle in Power System Mode Analysis
}

\author{
Anatoly Mahnitko, Riga Technical University, Alexander Gavrilov, Riga Technical University
}

\begin{abstract}
The optimal power dispatch problem in the power system is looked out in the given work. The mathematical model of power system optimal regime searching approach in the market conditions in accordance with Pareto principle is described. The theoretical layout is illustrated on a real power system model of the united power system, which consists of 17 nodes and 21 lines. The procedure is realized using the GAMS software.
\end{abstract}

Keywords: power system, node, optimization, Pareto, cost function, power flow.

\section{INTRODUCTION}

The problem of power system operation under market conditions and competition is very important at the present time.

There is looked out the model of power system in free prices on electricity below. Each node is represented by station or group of stations. The aim of the whole system is to cover the given energy demand, and the aim of each node is to minimize expanses caused by energy generation. These two aims can lead to different levels of energy generation at each node. Two concepts are used to reflect optimal behavior of the whole system and every node [1] - [3]. Optimization calculations are performed using the Pareto principle.

\section{THE MATHEMATICAL MODEL}

It is assumed that the power system contains $n$ nodes, some of them are connected. In every node $i$ could be generation $x_{i}$ and demand $P_{i}$. Variable $P_{i}$ is bounded from above by value $\bar{x}_{i}$. The node cost function's form [1] is

$$
C_{i}\left(x_{i}\right)=\alpha_{i}+\beta_{i} x_{i}+\gamma_{i} x_{i}^{2}, \quad i=\overline{1, n} .
$$
law:

Generations $x_{i}$ and flows $y_{i j}$ must satisfy the first Kirchhoff

$$
x_{i}=P_{i}+\sum_{j=1}^{n} a_{i j} y_{i j}-\sum_{j=1}^{n} a_{j i}\left(1-\pi_{j i}\right) y_{j i}, \quad i=\overline{1, n}
$$

where $P_{i}-$ the load at the node $i$.

Elements $a_{i j}$ of the connection matrix $A$ are given by

$$
a_{i j}= \begin{cases}1, & \text { if nodes } i \text { and } j \text { are connected, } \\ 0, & \text { otherwise }\end{cases}
$$

Variables $y_{i j}$ and $c_{i j}$ mean the energy flow from node $i$ to node $j$ and energy price, associated with the flow $y_{i j}$. Constants $\pi_{i j}$ are loses coefficients

$$
\pi_{i j}=\frac{R_{i j}}{U_{i} \cdot U_{j}} \cos \delta_{i j},
$$

where $\delta_{i j}$ - phase displacment angles between voltage vectors $U_{i}$ and $U_{j}$;

$R_{i j}$ - active resistance of line between nodes $i$ and $j$.

I.e. value $\pi_{i j} y_{i j}$ gives the part of the flow $y_{i j}$, which was lost during transmission from node $i$ to node $j$. [4]:

The total expenses can be expressed in the following form

$$
\begin{gathered}
C_{\sum_{i}}\left(x_{i}, y_{i j}, y_{j i}, c_{i j}, c_{j i}\right)=C_{i}\left(x_{i}\right)-\sum_{j=1}^{n} a_{i j} c_{i j} y_{i j}+ \\
+\sum_{j=1}^{n} a_{j i} c_{j i} y_{j i}+\frac{1}{2} \sum_{j=1}^{n} a_{i j} \pi_{i j} c_{i j} y_{i j}+\frac{1}{2} \sum_{j=1}^{n} a_{j i} \pi_{j i} c_{j i} y_{j i} .
\end{gathered}
$$

The first term of (3) gives the expenses, caused by generation of $x_{i}$ units of energy. The second term gives the profit from the sold energy. The third term in (3) discloses expenses connected with the bought energy. In this work is assumed that expenses, corresponding to loses of energy, are equally separated by seller and buyer. This is the reason of appearance of the forth and fifth terms in the expression (3).

For the mathematical model of power system is assumed that the following inequality is true

$$
P_{i} \leq \bar{x}_{i}, \quad i=\overline{1, n}
$$

where $\bar{x}_{i}$ - the maximal power of the power plant.

The main problem is formulated as the following multicriteria optimization problem [4]:

$$
C_{\Sigma_{1}}\left(x_{1}, y_{1 j}, y_{j 1}, c_{1 j}, c_{j 1}\right) \rightarrow \min ,
$$

$$
C_{\sum_{n}}\left(x_{n}, y_{n j}, y_{j n}, c_{n j}, c_{j n}\right) \rightarrow \min ,
$$

$$
x_{i}=P_{i}+\sum_{j=1}^{n} a_{i j} y_{i j}-\sum_{j=1}^{n} a_{j i}\left(1-\pi_{j i}\right) y_{j i}, \quad i=\overline{1, n},
$$




$$
\begin{gathered}
y_{i j} y_{j i}=0, \quad i, j=\overline{1, n}, \\
C_{i}^{\prime}\left(x_{i}\right) y_{i j} \leq c_{i j} y_{i j} \leq C_{j}^{\prime}\left(x_{j}\right) y_{i j}, \quad i, j=\overline{1, n}, \\
0 \leq x_{i} \leq \bar{x}_{i}, \quad i=\overline{1, n}, \\
0 \leq y_{i j} \leq \bar{y}_{i j}, \quad i=\overline{1, n .}
\end{gathered}
$$

Constraint (7) forbids simultaneous flows in opposite directions at the same line. The value $\bar{y}_{i}$ defines the maximum available flow between nodes $i$ and $j$.

Energy transmission from the node $i$ to $j$ is suitable for both nodes if the price $c_{i j}$ satisfy the inequality

$$
C_{i}^{\prime}\left(x_{i}\right) \leq c_{i j} \leq C_{j}^{\prime}\left(x_{j}\right)
$$

Problem (5-10) is a difficult mathematical programming multicriteria problem. Moreover, in this problem prices $c_{i j}$ are variables. Hence, as soon as we have terms $c_{i j} y_{i j}$ we meet bilinearity that complicates the problem from the optimization point of view. In general, bilinearity leads to multiextremality - solution with many local optima. Other sources of bilinearity are constraints (7) and (8). In such case, to overcome the bilinearity, a global optimization approach can be used.

\section{PARETO OPTIMALITY CONSIDERATION IN THE OBJECTIVE FUNCTION}

A strategy vector

$$
x^{p}=\left(x^{p 1}, \ldots, x^{p n}\right)
$$

is said to be Pareto optimal if there are no other strategy vectors $x=\left(x^{1}, \ldots, x^{n}\right) \in X$ such that

$$
f_{i}(x) \leq f_{i}\left(x^{p}\right), \quad i=\overline{1, n}
$$

and

$$
f_{k}(x)<f_{k}\left(x^{p}\right)
$$

for some $k \in\{1,2, \ldots, n\}$ [2].

If we take constraints $\mu_{i}>0, i=\overline{1, n}$ (constants $\mu_{i}$ are weights or importance of each loss function) and solve the problem

$$
\sum_{i=1}^{n} \mu_{i} f_{i}(x) \rightarrow \min , \quad x \in X
$$

then the obtained optimal solution is a Pareto optimal solution.

In our settings every node is a player. We suggest to consider the generation $x_{i}$ of node $i$, energy flows $y_{i j}$ from node $i$ to neighbor nodes and associated prices $c_{i j}$ as the strategy of node $i$. In order to find a Pareto optimal solution function (12) subject to constraints (6-10) should be minimized. From this point of view we have from (3) that the loss functions in the model are also separable. Then from (12) the following function could be obtained:

$$
\sum_{i=1}^{n} C_{i}\left(x_{i}\right)-\sum_{i=1}^{n} \sum_{j=1}^{n} a_{i j} c_{i j} y_{i j}+\frac{1}{2} \sum_{i=1}^{n} \sum_{j=1}^{n} a_{i j} \pi_{i j} c_{i j} y_{i j} \rightarrow \min
$$

Minimization of function (13) can be interpreted as follows. In the objective function (13) the first term (total costs) and the third term (expenses of total loses) are minimized, while the second term (expenses of total transmission) due to minus before the term is maximized.

The considered mathematical programming problems for finding the Pareto optimal solutions are nonconvex and, hence, van has many local optima. In order to find the global optimum optimization technique is used [5]. This technique is based on the general branch and bound scheme, when multiextremal problem is approximated by a sequence of convex or one-extreme problems.

\section{EXAMPLE OF CALCULATIONS}

The optimization model is looked out on the power system test scheme. The scheme represents real integrated power system of Latvia, Estonia, Russia and Lithuania (Fig.1). In the given scheme Latvian power system is represented by ten substations, Estonian power system by three substations, but part of the Russian power system - by three substations. Power generators connected to buses of the net are shown as red cycles. The power system of Lithuania is represented by equivalent power in the node LIKSNA. Such approach of nodal power system model representation provides correspondence of regime parameters to the whole integrated power system in the field of research and facilitates analysis of regimes. Lines' active resistances are shown on the Fig. 1. The rated voltage of the net is $U_{n}=330 \mathrm{kV}$. Active power generation limits on power plants are:

$$
\begin{gathered}
200 \leq P_{\text {Eesti }} \leq 1200 \mathrm{MW} \\
200 \leq P_{\text {Balti }} \leq 765 \mathrm{MW} ; \\
100 \leq P_{R . H P P} \leq 400 \mathrm{MW} ; \\
100 \leq P_{P l . H P P} \leq 865 \mathrm{MW} .
\end{gathered}
$$

Power lines' carrying capacity was limited on $300 \mathrm{MW}$. Reactive power flows and power system elements' reactive resistances are not taken into account during the calculations.

There was modeled the given regime of the model during the first stage. Normal active power dispatch is shown on the Fig. 1. The regime was coded using General Algebraic Modeling System (GAMS) language. GAMS is a high level language for developing mathematical models with concise algebraic statements. It makes use of relational database theory and mathematical programming and further merges them to suit need of mathematical modelers. Apart from a 


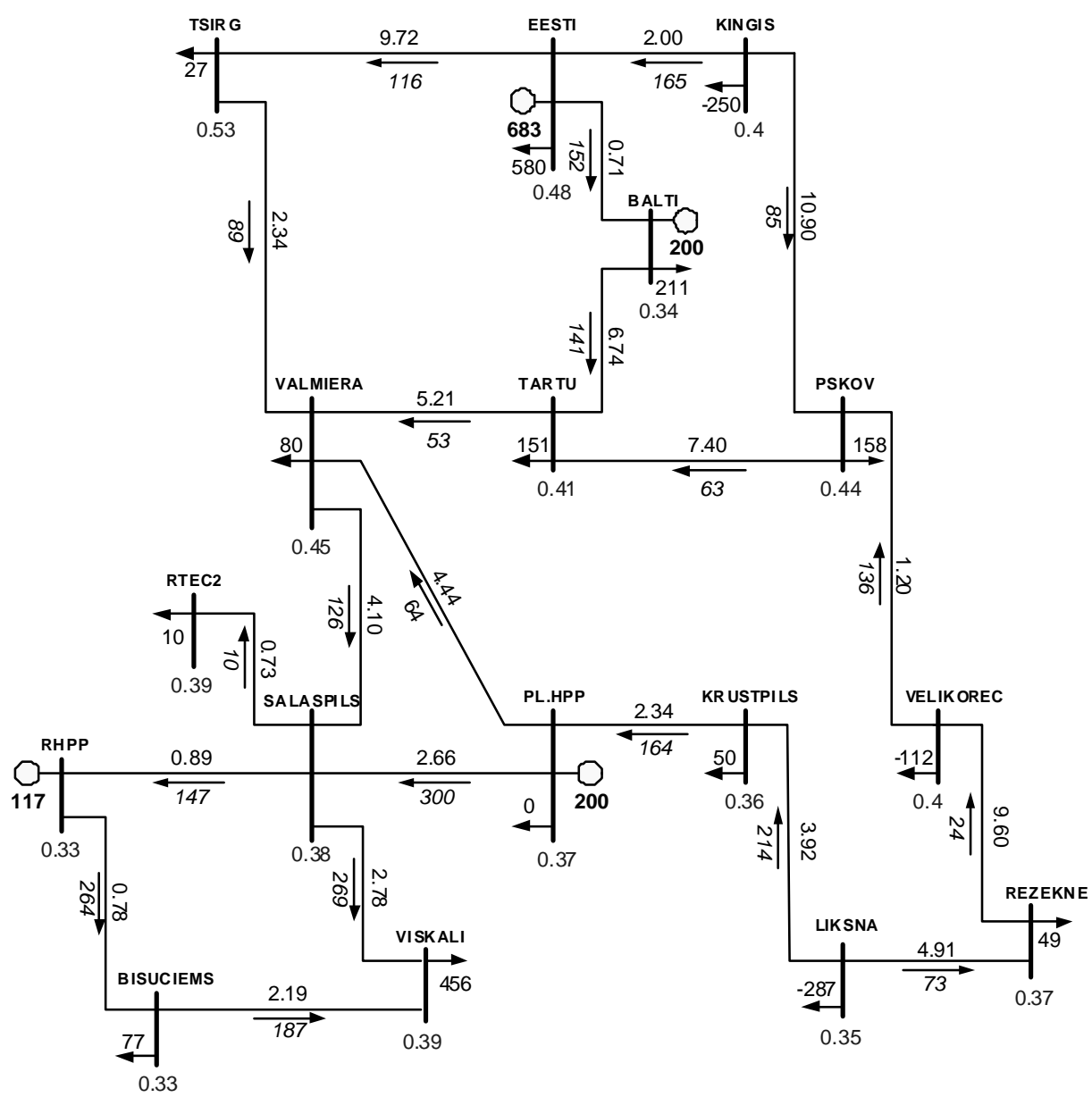

Fig. 1. Real power system model

wide variety of optimization problems, it can handle simultaneous linear and non-linear equation systems [6, 7].

Power supply cost characteristics are accepted as follows:

$$
\begin{gathered}
C_{\text {Eesti }}=200+0.14 \cdot P_{\text {Eesti }}+0.00025 \cdot P_{\text {Eesti }}^{2} ; \\
C_{\text {Balti }}=200+0.23 \cdot P_{\text {Balti }}+0.0003 \cdot P_{\text {Balti }}^{2} \cdot \\
C_{R H P P}=100+0.12 \cdot P_{R H P P}+0.0009 \cdot P_{R H P P}^{2} ; \\
C_{P L H P P}=100+0.11 \cdot P_{P L H P P}+0.00065 \cdot P_{P L H P P}^{2} .
\end{gathered}
$$

Marginal price in the nodes $c_{i}$ of the power system are gotten as the first derivative from aggregate cost characteristics:

$$
c_{i}=C_{i}^{\prime}\left(P_{i}\right)
$$

where $i$ - power supply (in our model those nodes are Eesti, Balti, RHPP, Pl.HPP).

For nods with power transit marginal prices were accepted at the level: 0.35 for the node Liksna, 0.4 for nodes Velikorec and Kingis.
During the calculations of marginal prices for nodes without generating sources it was established that marginal price in the node increases by $1 \%$ as to the nearest node with power generation for every $1 \Omega$ of line's resistance in the direction of power flow. Nodal marginal prices are displayed on Fig. 1.

It was assumed that all nodes have equal importance, i.e. weight coefficients are $\mu_{i}=1$. The Pareto problem according to (13) was modeled in GAMS software. Solving the Pareto problem optimal economic dispatch that is shown on the Fig. 2 was gotten.

From the gotten results we can see that after power system mode optimization in accordance with Pareto principle in the market conditions the generation and power flows in the system have changed. For all to see, before mode optimization marginal prices in some nodes of the power system are grater, than power flow prices from those nodes. That's why nodes with higher nodal prices than power flows' prices in direction to nodes, are interested in price increase. After regime optimization marginal prices in generation nodes became equal and prices of power flows in the network satisfy the inequality (11). 


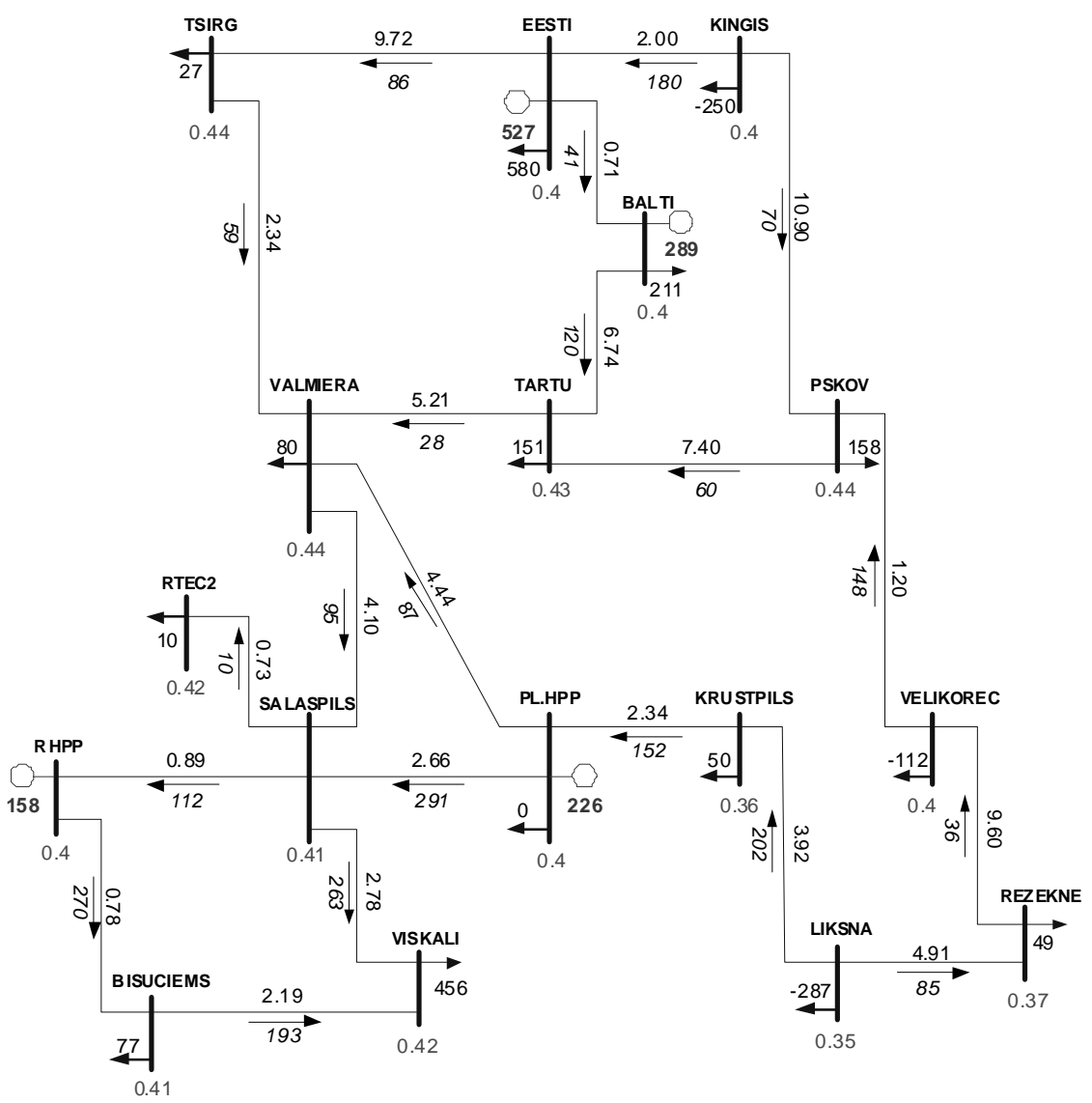

Fig. 2. Real power system scheme after modeling

\section{CONCLUSIONS}

Developed algorithm allows observing criteria of total costs on generation and loses expenses in the network minimization and profit maximization in the efficiency function of optimization task.

The algorithm's approbation on the $330 \mathrm{kV}$ network of the real Baltic power system example at the accepted main power plants' cost characteristics gave proof about its disability.

This work has been supported by the European Social Fund within the project ,Support for the implementation of doctoral studies at Riga Technical University”.

\section{REFERENCES}

[1] Ананичева С.С., Мызин А.Л., „Модели развития электроэнергетических систем," Екатеринбург, 2005, 75 с.

[2] Бартоломей П.И., Паниковская Т.Ю., „Оптимизация режимов энергосистем," Екатеринбург: УГТУ- УПИ, 2008, 164 с.

[3] Летун В.М., Глуз И.С., „Оптимальное управление режимом работы электростанций в условиях оптового рынка," Электрические станции, №3, 2003, с. 8-12.

[4] Khamisov O.V., "An optimization approach to finding the Pareto optimal and Nash equilibrium solutions in a mathematical model of energy system functioning," IEEE, Liberalization and Modernization off Power Systems, Operation and Control Problems, The International Workshop Proceedings, Irkutsk, Energy Systems Institute, 2000, p. 84-88

[5] Neumaier A., "Complete search in continuous global optimization and constraint satisfaction," Acta Numerica 2004 (A. Iserles, ed.), Cambridge, 2004, 94 p.
[6] Брук А., Кендрик Д., Меераус А., Раман Р., „Руководство по GAMS,” (русская версия), ентральноазиатская миссия агенства США по международному развитию, 1999, 172 с

[7] Chattopadhyay D., "Application of general algebraic modeling system to power system optimization," IEEE Transactions on Power Systems, Vol.14, No.1, 1999, pp. 15-18.

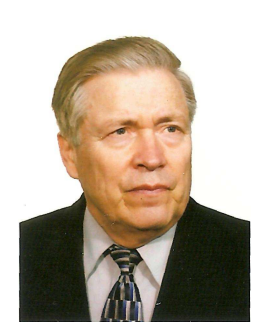

Anatoly Mahnitko was born in Dnepropetrovsk, Ukraine on February $15^{\text {th }}$ in 1942 . He graduated from Mechanics and Mathematics Faculty of Kiev State University. In 1972 he received Ph.D. in electrical engeneering and Dr.Sc.Ing. in 1992 at Riga Technical University (RTU). He has been working in RTU since 1972 as a senior lecturer, Assistant, Associate Professor and Professor of the Institute of Power Engineering.

His research interests include electric power system mathematical simulation and optimization. Phone: +371 7089938, fax: +371 7089931. E-mail: mahno@eef.rtu.lv

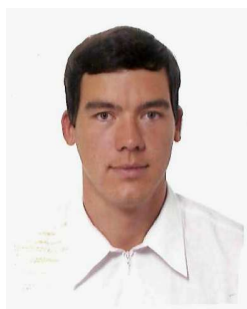

Alexander Gavrilov was born in Daugavpils, Latvia, on July $24^{\text {th }} 1984$. He received M.Sc.Ing. in Electrical Engineering from Faculty of Power and Electrical Engineering of Riga Technical University (RTU) in 2007. He is currently a doctoral student of RTU.

His research field is power system optimization, planning and simulation.

Phone: +37126161738. E-mail:a.gavrilovs@inbox.lv 